\title{
Rafting by five phyla on man-made flotsam in the Southern Ocean
}

\author{
David K. A. Barnes*, Keiron P. P. Fraser \\ British Antarctic Survey, Natural Environment Research Council, High Cross, Madingley Road, Cambridge CB3 0ET, UK
}

\begin{abstract}
In just 4 decades, marine litter has become abundant in northern oceans and seas and is increasing on even remote Southern Ocean island shores. The Southern Ocean was thought to be protected from rafting organisms by its freezing sea surface temperatures. Here we report on an assemblage of animals attached to a piece of plastic that was washed ashore on Adelaide Island, Antarctic Peninsula $\left(68^{\circ} \mathrm{S}\right)$. The band of plastic was positively buoyant. At least 10 species belonging to 5 phyla were present on the plastic and the size of some indicated that it had been afloat for more than a year. Clearly it is possible for a range of animals to survive and grow in such an environment, and so exotic species could enter or leave the Southern Ocean.
\end{abstract}

KEY WORDS: Marine debris $\cdot$ Plastic $\cdot$ Invasive species $\cdot$ Antarctica Resale or republication not permitted without written consent of the publisher

\section{INTRODUCTION}

Over the past 4 decades there has been a massive invasion of floating plastic litter in the marine environment, with potentially significant consequences for the transport of invasive species. The only shores and sea surfaces free of persistent plastics were, until recently, at high, southern polar, latitudes (Gregory et al. 1984), where it was thought that the Polar Frontal Zone (PFZ) might act as a barrier to surface transport. However, driftwood and fishing-related castoff materials have now crossed the PFZ in both directions (Barber et al. 1959, Coombs \& Landis 1966), which raises the possibility for transport of organisms into the Southern Ocean, the only marine realm for which no manmediated invaders are yet known. Floating at the surface and at the interface of variable air temperatures and freezing surface temperatures would seem likely to make it hard for animals to colonize this potential transport. Colonization of high latitude drift debris is very low (Barnes 2002) and no biota has been described from the many surveys of rubbish washing ashore on northern-most Antarctic islands (Gregory et al. 1984, Convey et al. 2002). Here we describe the first report of persistant colonizers on floating plastic in the Southern Ocean.

\section{DEBRIS ANALYSIS}

In February 2003 we found and examined a piece of debris (only the 4th we know of in $5 \mathrm{yr}$ ) that was washed ashore on Adelaide Island, Antarctic Peninsula $\left(68^{\circ} \mathrm{S}\right)$. This was a piece of plastic packaging band (Fig. 1) of the sort used extensively by Antarctic bases and fishing boats and has commonly been found entangling seals (Bonner \& McCann 1982). Placement of the band in the sea confirmed that it was positively buoyant. The fact that this plastic band was colonized is highly unusual-only rarely, and then at latitudes $<60^{\circ} \mathrm{S}$, have there been reports of anthropogenic debris in the Southern Ocean colonized by fauna. Such reports have only mentioned stalked (lepadomorph) barnacles (MacIntyre 1966, M. Schulz \& H. Burton 
unpubl.). On this Antarctic debris we found 5 cheilostomatid bryozoans, 2 demosponges (Porifera), 2 polychaetes (Annelida), a hydroid (Cnidaria) and a small gastropod (Mollusca). Colonization had taken place within the Southern Ocean, as the gastropod Laevilitorina antarctica and all 5 bryozoans (Aimulosia antarctica, Arachnopusia inchoata, Ellisina antarctica, Fenestrulina rugula and Micropora brevissima) present are endemic to the Southern Ocean. None have ever been described colonizing floating material before, and only 1, A. antarctica, has been found in the intertidal zone (Barnes et al. 1996). The large size of the $M$. brevissima colonies (>20 mm wide) is strong evidence that the item of debris had been in the water for at least 1 yr (by comparison with the same species on monitored panels and natural substrata: see Barnes et al. 1996). One A. inchoata and 1 E. antarctica colony each occupied an area of $>100 \mathrm{~mm}^{2}$, which suggested that they were also at least $1 \mathrm{yr}$ old (see Stanwell-Smith \&

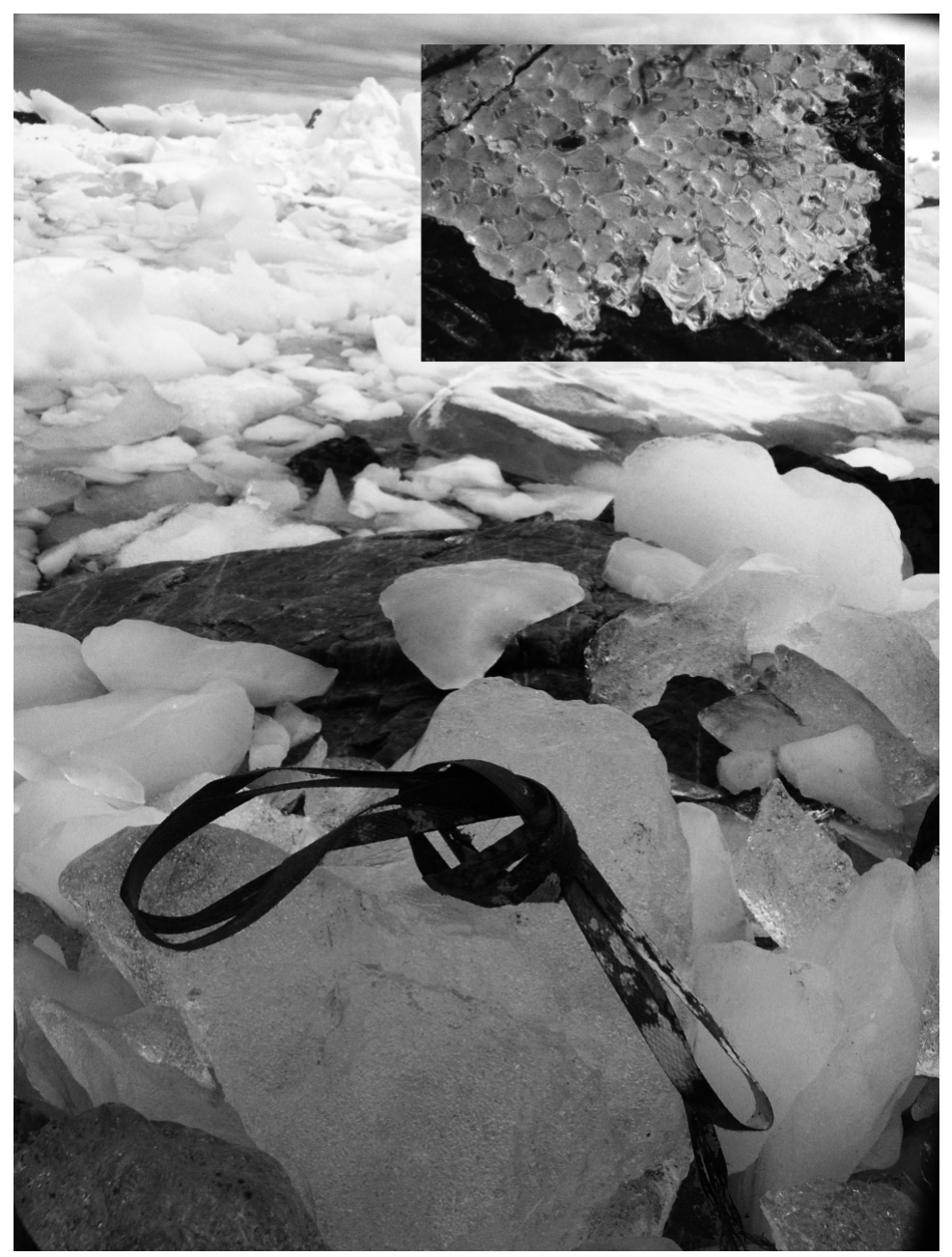

Fig. 1. The piece of plastic packaging band washed up on on the icestrewn shore of Adelaide Island, Antarctic Peninsula $\left(68^{\circ} \mathrm{S}\right)$. Inset: a colony of Micropora brevissima on the band of plastic
Barnes 1997). All or most colonies of the bryozoans $E$. antarctica, F. rugula and $M$. brevissima were reproductively active (ovicells were present) on discovery, and thus it is likely that they would have been able to release larvae whilst floating on the debris. This finding demonstrates that it is at least possible for Southern Ocean flotsam, like debris in warm waters, to carry a diverse range of animal taxa and sizes (Jokiel 1990, Winston et al. 1997, Barnes 2002).

We suspect that the plastic packaging band had drifted for more than $1 \mathrm{yr}$ in the Antarctic Peninsula region and was colonized by benthic taxa due to a localized uplifting of larvae by ice action. Dayton (1989) reported colonization of mid-water settlement panels by this process. An alternative hypothesis is the possibility that the band was trapped underwater (under ice or attached to negatively buoyant material), was colonized and then floated back up, as has been known to happen elsewhere (J. Carlton pers. comm.). The fouling biota found on the debris was distributed evenly, which suggests that no part was buried or inaccessible to colonists.

Some marine debris, both natural and anthropo-genic, undoubtedly travels up into the Atlantic, Indian and Pacific Oceans. In comparison with many water column or sea surface boundaries, the PFZ is substantial but flotsam does cross it in both directions (Barber et al. 1959, Coombs \& Landis 1966). As the thermal tolerance of most Antarctic benthos, which has been measured, is very low (Peck 2002), it is unlikely that these stenothermal animals are going to be successful invading the warm and eurythermal conditions to the north. Notably a number of fouling bryozoans have been shown to be capable of surviving up to $10^{\circ} \mathrm{C}$ (Barnes et al. 1996). There may, however, be a number of cool temperate species which may be capable of rafting into the Southern Ocean and surviving. Both lepadomorph barnacles (Minchin 1996) and various encrusting taxa (Winston et al. 1997) seem to be taking the opportunity of this expanding niche in other oceans. Assuming that the colonist can survive depleted food abundances (unshown to date) far from coastal conditions, marine debris has the potential to transport larvae vast distances at a slow pace. Such speed may be important in improving the survival prospects, as organisms are more likely to be able to cope with changes in the environment when they are slowly introduced. 


\section{CONCLUSIONS}

The marine environment surrounding the Antarctic continent remains a last frontier (no exotic species are yet known to have invaded). Regions of highest endemism are probably those most threatened by invasive species, and Antarctic waters have very high levels of species endemism (Winston 1992). Antarctica may have been isolated for 10s of millions of years but potential colonists travelling in the air as spores, on migrating megafauna, on ships or on the ubiquitous debris may have more chance of establishing themselves now due to warming in the area. The terrestrial environment of many subantarctic islands already supports a few naturally and man-mediated introduced species. As with islands in the southern Atlantic (Ryan \& Moloney 1993) marine litter has become a prolific new polar pioneer (Convey et al. 2002). There have, no doubt, been numerous mass releases of floating air-filled rock after volcanic explosions (see Coombs \& Landis 1966) but these are rare and unpredictable in space and time. Other than these there are few natural sources of flotsam (no native floating mollusc shells, seeds, fruits or trees).

Our finding demonstrates for the first time that a wide range of species and higher taxa can survive the air-sea interface on the surface of the Southern Ocean and that they can colonize marine debris as elsewhere in the world. Such a range of higher taxa on a single (and small) item would be exceptional even at low latitudes (Winston et al. 1997, Barnes 2002). We also show that such debris colonists can survive through the southern polar winter; the colonist sizes represented animals at least $1 \mathrm{yr}$ old. Finally we present the first evidence that polar hitchhikers on debris can reach maturity - so are potentially able to colonize new habitats wherever they drift to. This is an important mechanism because the 4 bryozoan species have larvae-essentially benthic, thus typifying species - which would not be expected to spread widely. The small proportion of debris colonized by fauna could be enough to bring in polar invaders if the amount of marine debris is large enough. It seems that nowhere is the proportion of debris of anthropogenic origin higher than at high southern latitudes (Barnes 2002). Changes in the thermal characteristics of Southern Ocean surface water are difficult to predict, but some models suggest a 2 to $4^{\circ} \mathrm{C}$ increase within the next century (Murphy \& Mitchell 1995). Such a rise in temperature could have a drastic impact on the survival prospects of invaders.
Acknowledgements. The authors thank Profs. L. Peck and J. Carlton and 3 anonymous referees for constructive comments leading to a much improved manuscript.

\section{LITERATURE CITED}

Barber HN, Dadswell HE, Ingle HD (1959) Transport of driftwood from South America to Tasmania and Macquarie Island. Nature 184:203-204

Barnes DKA (2002) Invasions by marine life on plastic debris. Nature 416:808-809

Barnes DKA, Rothery PJ, Clarke A (1996) Colonisation and development in encrusting communities from the Antarctic intertidal and sublittoral. J Exp Mar Biol Ecol 196: 251-265

Bonner WN, McCann TS (1982) Neck collars on fur seals, Arctocephalus gazella, at South Georgia. Br Antarct Surv Bull 57:73-77

Convey P, Barnes DKA, Morton A (2002) Debris accumulation on oceanic island shores of the Scotia Arc, Antarctica. Polar Biol 25:612-617

Coombs DS, Landis CA (1966) Pumice from the South Sandwich eruption of March 1962 reaches New Zealand. Nature 209:289-290

Dayton P (1989) Interdecadal variation in an Antarctic sponge and its predators from oceanographic climate shifts. Science 245:1484-1486

Gregory MR, Kirk RM, Mabin MCG (1984) Pelagic tar, oil, plastics and other litter in surface waters of the New Zealand sector of the Southern Ocean and on Ross Dependency shores. NZ Antarct Record 6:12-28

Jokiel PL (1990) Long-distance dispersal by rafting: reemergence of an old hypothesis. Endeavour 14:66-73

MacIntyre (1966) Rapid growth in stalked barnacles. Nature 212:637-638

Minchin D (1996) Tar pellets and plastics as attachment surfaces for lepadid cirripedes in the North Atlantic Ocean. Mar Pollut Bull 32:885-859

Murphy JM, Mitchell JFB (1995) Transient response of the Hadley Centre coupled ocean-atmosphere model to increasing carbon dioxide. J Climate 8:36-514

Peck LS (2002) Ecophysiology of Antarctic marine ectotherms: limits to life. Polar Biol 25:31-40

Ryan PG, Moloney CL (1993) Marine litter keeps increasing. Nature 361:23

Stanwell-Smith D, Barnes DKA (1997) Benthic community development in Antarctica: recruitment and growth on settlement panels at Signy Island. J Exp Mar Biol Ecol 212: 61-79

Winston JE (1992) Systematics and marine conservation In: Eldridge $\mathrm{N}$ (ed) Systematics, ecology and the biodiversity crisis. Columbia University Press, New York, p 144-168

Winston JE, Gregory MR, Stevens LM (1997) Encrusters, epibionts and other biota associated with pelagic plastics: a review of biogeographical, environmental and conservation issues. In: Coe JM, Rogers DB (eds) Marine debris: sources, impact and solutions. Springer-Verlag, New York, p 81-97

Submitted: May 23, 2003; Accepted: September 7, 2003

Proofs received from author(s): October 31, 2003 